\title{
Solar Home System with Diversified Roofing Construction
}

\author{
Hamzah Eteruddin*, David Setiawan, Atmam, Burhan Nasution \\ Department of Electrical Engineering, Lancang Kuning University, Indonesia
}

Received October 7, 2019 ; Revised December 5, 2019; Accepted December 12, 2019

\begin{abstract}
Copyright@2019 by authors, all rights reserved. Authors agree that this article remains permanently open access under the terms of the Creative Commons Attribution License 4.0 International License
\end{abstract}

\begin{abstract}
Conventional power plants generally emit Greenhouse gases (GHGs) that potentially pollute the environment. Solar Home Systems (SHS) are electrical appliances capable of generating electrical energy by absorbing the sunlight radiation. The operation of Solar Home Systems does not result in pollution. The unlimited amount of solar radiation in our nature makes Solar Home Systems affordable and eco-friendly. In this research, we implemented these Solar Home Systems as a household power supply by taking advantage of diversified roofing conditions in a residential area in Lembah Damai village, Rumbai Pesisir district, Pekanbaru. Different directions and angles of the solar radiation receiver affected the energy output. Observing electrical energy output in five houses as the subject of the research, we found out that House 4's on the side-B roof with a 24-degree inclination and a 72-degree orientation generated the highest power output amounting to 1,265 kWh/yr. Meanwhile, House 2's side-A roof with a 28-degree inclination of and 239-degree orientation generated the lowest power output amounting to $1,073.9 \mathrm{kWh} / \mathrm{yr}$. Thus, the fluctuation accounted for $17.8 \%$.
\end{abstract}

Keywords Iradiation, Radiation, Solar Cell, Sunlight Angle

\section{Introduction}

Concerns about fossil energy sources highly thinning out have become a key reason for the people to take advantage of and empower renewable energy sources. With an adequate amount of availability, renewable energy sources should be utilized more optimally to meet the society's energy needs.

When Implementing a solar power plant on a household especially in a residential area with diversified roofing constructions and conditions such as in Lembah Damai village, Rumbai Pesisir district, Pekanbaru, we must calculate things properly. The position of solar panels is a major research highly noted in designing a solar power plant since any solar radiation on the roof positively or negatively impacts on the Solar Home Systems' electricity generation. The results of this research will positively contribute to the development and utilization of renewable energy to meet the society's electrical energy needs.

Radiation is the amount of solar energy existing in per area unit. When the process occurs for a certain period of time, it is called irradiation or insolation [1]-[3]. intensity of the solar radiation outside the Earth's atmosphere is influenced by the distance between the Sun and the Earth for one year. The distance between them varies from $1.47 \mathrm{x}$ $10^{8} \mathrm{~km}$ to $1.52 \times 10^{8} \mathrm{~km} \mathrm{[4]-[6].} \mathrm{Changes} \mathrm{in} \mathrm{the} \mathrm{distance}$ will result in changes in the radiation occurring outside of the Earth's atmosphere (extraterrestrial radiation). Therefore, the average radiation value is deemed to be a constant of $\mathrm{G}_{\mathrm{SC}}=1,367 \mathrm{~W} / \mathrm{m}^{2}[9]-[11]$

\subsection{Data Calculation Stages}

In this research, the data calculation process was comprised of several stages. To make it easier for us to understand that process, Figure 1 showed us the flowchart of those calculation stages. We could see that the raw data consisted of eight parts namely orientation angle, solar clock angle, declination, slope angle, global extraterrestrial irradiance, hourly global horizontal irradiance, reflected value and ambient temperature. The data would subsequently be used as the basic variables for each of the following stages based on the flow in the flowchart. Therefore, we obtained the amount of energy generated by the PV module from the results of the calculation. 


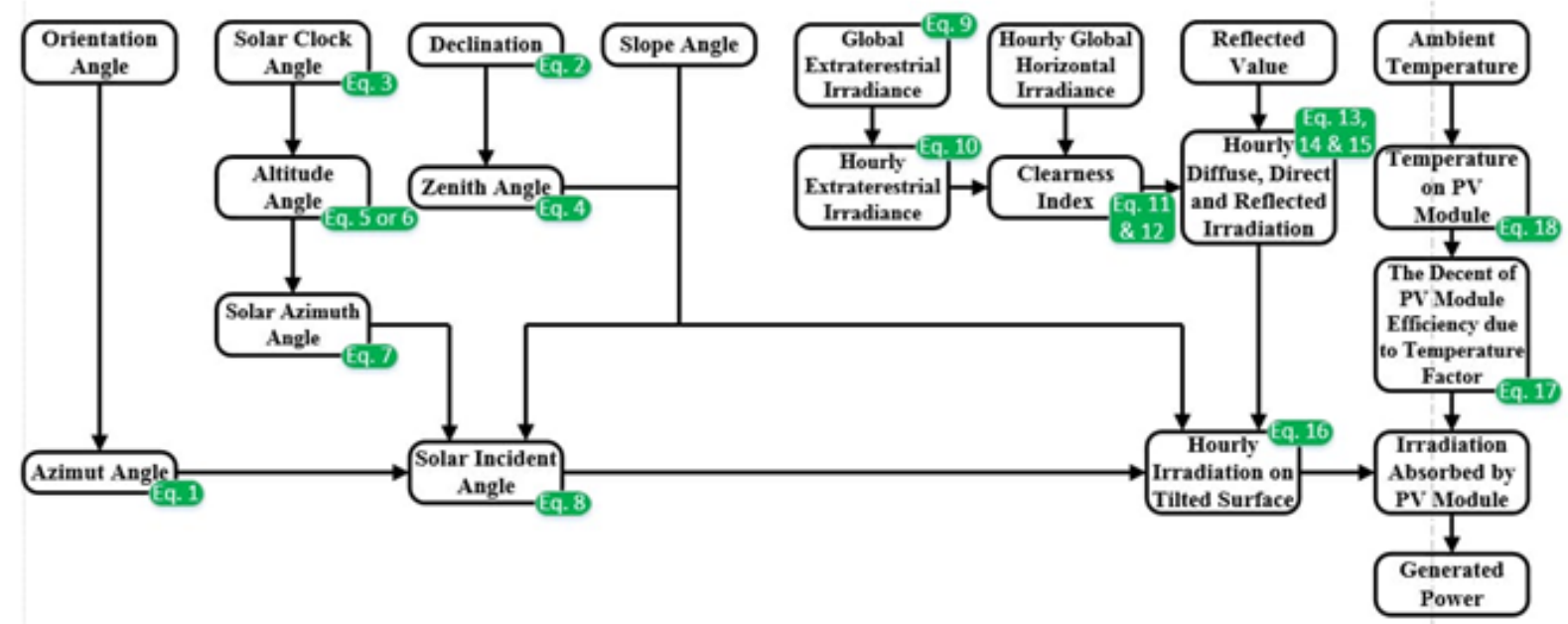

Figure 1. Flowchart of calculation stages in this research

To more deeply understand the stages shown in Figure 1, the following theories will elaborate that the roles of each part of the flowchart are, to a large extent, divided into three main parts namely sunlight angle, the sunlight irradiation and environmental temperature.

\section{Sunlight Angle}

Solar movement is an issue that should concern us especially in the phase of positioning a PV (Photovoltaic) module. The selected location not in line with the maximum sunlight angle will result in the less optimum output. To ensure a good position of the PV module, we must first acquire the knowledge of the relative solar location which is in the form of an angular magnitude. Below are the angles.

\section{Azimuth Angle $(\gamma)$}

It is the projection of the normal horizontal field against the longitude surface, the azimuth angle value is $-180 \mathrm{o} \leq \gamma$ $\leq 180$ o, with zero degrees facing south, negative for the east side, and positive for west side [9]. The azimuth angle value can be calculated with equation 1 below:

$$
\gamma=O_{r}-180^{\circ}
$$

Where: Or $=$ Orientation Angle

\section{Declination $(\delta)$}

It is the solar position angle toward the Equator. The declination angle value is-23.450 $<\Delta<23.450$. The (-) value signifies the South Side and the $(+)$ value signifies the north side [9]. The following equation 2 has resulted in the value declination angle [12]:

$$
\delta=23,45^{\circ} \sin \left(360 \frac{284 \times n}{365}\right)
$$

Where: $\mathrm{n}=$ days in a year

\section{Solar Clock Angle ( $\omega)$}

It is the solar deviation angle on the east or west of the local longitude since the rotation on the axis is $15^{\circ}$ per hour; before 12 am is negative, and after at 12 am is positive value [9]. The solar clock angle is calculated using the equation 3 below [13]:

$$
\omega=15 \times(L t-12)
$$

Where: $\mathrm{Lt}=$ the duration (in hour)

Latitude $(\varphi)$ and Longitude (L) Angles

They are two angles used to describe the geographical coordinates of a location. Latitude is the ring line that splits the equator and perpendicular to the Earth's rotation point, the northern side is positive $(+)$ and the southern side is negative (-). Meanwhile, longitude is the line of the circumference which is in line with the equator but cuts the Earth's rotation line, the western side is positive $(+)$ and the eastern side is negative (-). The value of latitude and longitude angles is in the range from $-180^{\circ}$ to $180^{\circ}$.

\section{Zenith Angle $(\theta z)$}

It is an angle between the vertical lines of a normal medium (Zenith) and the landing line of sunlight [9]. The value of the zenith angle is calculated using equation 4 [13]

$$
\theta z=\operatorname{Cos}^{-1}\left(\begin{array}{l}
\cos \varphi \times \cos \delta \times \cos \omega \\
+\sin \varphi \times \sin \delta
\end{array}\right)
$$

Where: $\varphi=$ Latitude angle, $\delta=$ Declination angle, $\omega=$ Solar clock angle

\section{Altitude Angle (h)}

It is an angle between the horizontal lines of a normal medium and the sunlight coming line [13]. The value of the altitude angle is calculated using equation 5 [13]:

$$
\sinh =(\sin \delta \times \sin \varphi+\cos \varphi \times \cos \varphi \times \cos \omega)
$$

If the zenith angle value is stated, to calculate the altitude angle value, equation 6 below is applicable: 


$$
h=90-\theta z
$$

Solar Azimuth Angle ( $\alpha)$

It is the deviation angle from the south with the projection of direct radiation on the horizontal medium. The deviation directing to the East is negative and to the West is positive [9]. Equation 7 has resulted in the solar azimuth angle [13]:

$$
\sin \alpha=\frac{\operatorname{Cos} \delta \times \operatorname{Sin} \omega}{\operatorname{Cos} \mathrm{h}}
$$

Where: $\mathrm{h}$ = altitude angle

Slope $(\beta)$

It is an angle between the medium surfaces presented with a horizontal surface [9]. Slope can also be defined as a slope angle on the PV module on a flat medium.

Solar Incident Angle $(\theta)$

It is an angle between the light rays coming from the sun against the vertical axis of the collector surface field [9]. The following equation 8 has resulted in the solar incident angle [13]:

$$
\operatorname{Cos} \theta=\operatorname{Cos} \beta \cdot \operatorname{Cos} \theta z+\operatorname{Sin} \beta \cdot \operatorname{Sin} \theta z \cdot \operatorname{Sin}(\alpha-\gamma)
$$

Where: $\beta=$ Slope Angle, $\theta z=$ Zenith Angle, $\alpha=$ Solar Azimuth Angle, $\gamma=$ Azimuth Angle

\subsection{Hourly Extraterrestrial Irradiance}

It is a solar irradiation occurring outside the Earth's atmosphere. This irradiation value is affected by the distance between the sun and the earth. The value of extraterrestrial radiation as a constant is $\mathrm{G}_{\mathrm{SC}}=1,367 \mathrm{~W} / \mathrm{m}^{2}$. Equation 9 can be used to calculate the global extraterrestrial irradiation value which will be used to calculate the extraterrestrial irradiation value per hour using equation 10 [9].

$$
G_{O}=G_{S C} \times\left[1+0.033 \operatorname{Cos}\left(\frac{360 n}{365}\right)\right]
$$

where: $\mathrm{G}_{0}=$ Global extraterrestrial irradiation, $\mathrm{n}=$ days in a year, $\mathrm{Gsc}=$ the constant of global extraterrestrial irradiation

$$
I_{O}=G_{O} \times \operatorname{Cos} \theta z
$$

where: $\mathrm{I}_{\mathrm{O}}=$ Extraterrestrial irradiation per hour, $\theta \mathrm{z}=$ Zenith

\section{Clearness Index (K)}

It is a ratio of the global irradiation level per hour (I) to the extraterrestrial irradiation per hour $\left(\mathrm{I}_{\mathrm{O}}\right)$. This index is used to determine the atmospheric attenuation factor. In general, in a clean atmospheric condition, there is only a small part of split irradiation [14]. Equation 11 is used to determine the value of the clearness index $\left(k_{\mathrm{T}}\right)$ [9].

$$
k_{T}=\frac{I}{I_{o}}
$$

The key function of the Clearness Index is to determine the ratio value of diffusion irradiation (Id/I). The equation 12 below can be applied to calculate the ratio value of diffusion [9].

For $0<\mathrm{k}_{\mathrm{T}} \leq 0,22$

$$
\frac{I_{d}}{I}=(1-0.09 K) I
$$

For $0,22<\mathrm{k}_{\mathrm{T}} \leq 0,8$

$$
\left.\frac{I_{d}}{I}=\left(0,9511-0,1604 k_{T}+4,388 k_{T}{ }^{2}\right)-16,638 k_{T}{ }^{3}+12,336 k_{T}{ }^{4}\right) I
$$

For $0,8<\mathrm{k}_{\mathrm{T}} \leq 1$

$$
\frac{I_{d}}{I}=(0,165) I
$$

\subsection{Hourly Direct, Diffusion, and Reflected Irradiation}

Direct radiation, diffusion, and reflection are three elements that form radiation. The value can be determined by the use of equations 13,14 , and 15 . The ratio of the reflector material is required for the reflection irradiation. Table 1 contains the reflection value of some common material located in the surrounding area [14]-[16].

Table 1. Reflectance Value

\begin{tabular}{|c|c|}
\hline Ground Surface type & Reflectance $(\rho)$ \\
\hline Fresh Snow & 0.87 \\
\hline Dry Sand & 0.18 \\
\hline Wet Sand & 0.09 \\
\hline Coniferous Forest & 0.05 \\
\hline New Concrete & 0.33 \\
\hline Old Concrete & 0.23 \\
\hline
\end{tabular}

The research location was a residential area dominated by old buildings. Some of the yards were soil-surfaced, so the reflection value used was the average value between the dry sand (0.18) and the old concrete (0.23) namely p=0.2.

For Hourly Diffuse Irradiation $\left(\mathrm{I}_{\mathrm{d}}\right)$

$$
I_{d}=\left(\frac{I_{d}}{I} \times I\right)
$$

For Hourly Direct Irradiation $\left(\mathrm{I}_{\mathrm{b}}\right)$

$$
I_{b}=\left(1-\frac{I d}{I}\right) \times I
$$

For Hourly Reflected Irradiation (I $\rho)$

$$
I_{\rho}=\rho \times I
$$

\subsection{Hourly Irradiation on Tilted Surface (It)}

The irradiation level reaching the PV module is not 
entirely direct from the sun. Part of the solar radiation faces declining intensity due to diversification factors. With equations number 13, 14 and 15 above, we can calculate the hourly irradiation value on the slope surface with the following equation 16 [14]:

$$
I_{t}=\left(I_{b} \frac{\operatorname{Cos} \theta}{\operatorname{Cos} \theta z}\right)+\left(I_{d} \frac{1+\operatorname{Cos} \beta}{2}\right)+\left(I_{\rho} \frac{1-\operatorname{Cos} \beta}{2}\right)
$$

where: $\mathrm{I}_{\mathrm{b}}=$ Direct Irradiation, $\theta=$ Sun Incident Angle, $\theta \mathrm{z}=$ Zenith, $I_{d}=$ Diffusive Irradiation, $\beta=$ Slope Angle, $\mathrm{I} \rho=$ Reflective Irradiation

\subsection{The Decent of PV Module Efficiency Due to Temperature Factor}

During its operation, the temperature change in the PV module apparently affects the production of electrical energy. The higher the temperature goes, the more declining the voltage of the PV module output becomes [17]. It indirectly results in the descent of efficiency. Equation 17 is used to calculate the efficiency decent of the PV module due to a temperature factor [18].

$$
\eta_{c}=\eta_{\text {Tref }}\left(1-\beta_{\text {ref }}\left(T_{c}-T_{\text {ref }}\right)+\gamma \log _{10}(I)\right)
$$

Where: $\eta_{c}=$ Eficiency Losses due to Temperature Factor, $\eta_{\text {Tref }}=$ Electrical Efficiency, $\beta_{\text {ref }}=$ Temperature Coefficient, $\mathrm{T}_{\mathrm{c}}=$ Module Temperature, $\mathrm{T}_{\text {ref }}=$ Raw Test Temperature, $\gamma$ $=$ Radiation Coefficient, $\mathrm{I}=$ Irradiation

The common value of $\mathrm{T}_{\text {ref }}$ in the $\mathrm{PV}$ module is $25^{\circ} \mathrm{C}$, meanwhile, the average value of $\eta_{\text {Tref }}$ is $12 \%$ and the value of $\beta_{\text {ref }}$ is $0,0045{ }^{\circ} \mathrm{C}$ [17]. The three parameters mentioned are frequently stated on the specification of the PV module. To calculate the module temperature (Tc), equation 19 is applicable [19]-[21] :

$$
T c=T_{\mathrm{o}}+\left(D T \times \frac{I}{I_{S T C}}\right)
$$

Where: $\mathrm{T}_{\mathrm{c}}=$ Module Temperature, $\mathrm{T}_{\mathrm{o}}=$ Environment Temperature, DT = Offset Temperature, I = Irradation, $\mathrm{I}_{\mathrm{STC}}$ $=$ Raw Test Irradiation $\left(1000 \mathrm{Wh} / \mathrm{m}^{2}\right)$

\section{Research Method}

Kampung Bukit is a residential area in the city of Pekanbaru. It is located in Lembah Damai village, Rumbai Pesisir district on 0.575 North Latitude and dan 101.446 East Longitude. It is obvious that the sizes and the conditions of the buildings located there are different. With such conditions, the shape, direction, and slope of each house there are also different. Figure 2 depicts the location map of some of the inhabitants' houses in Kampung Bukit.

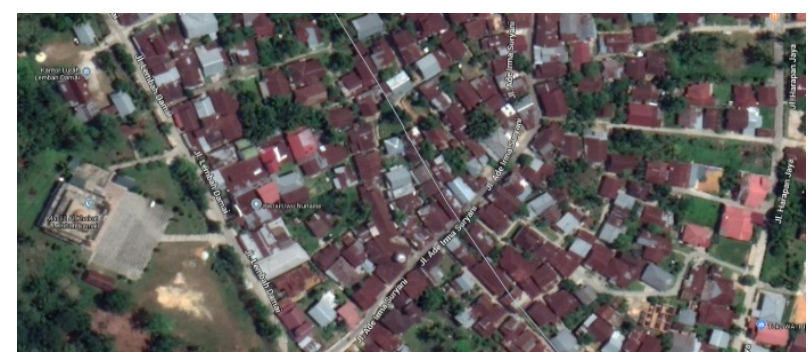

Figure 2. Kampung Bukit top views

Of dozens of houses in Kampung bukit, five houses were selected as subjects of the research on Solar Home System (SHS) in terms of their residential functions. Figure 3 showed us a photograph of those randomly-selected five houses.

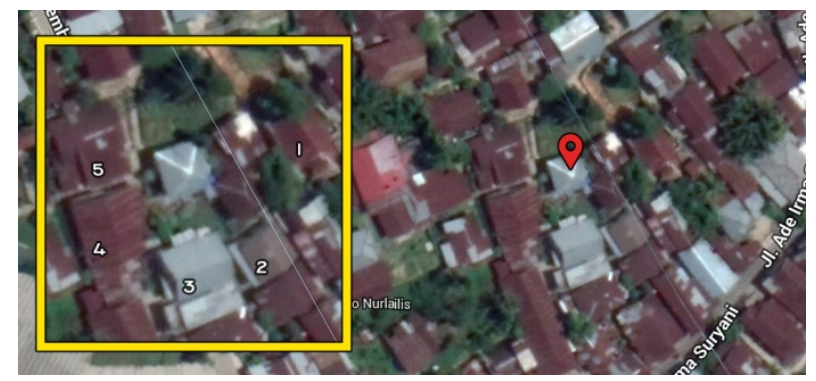

Figure 3. The Research Object Location

After measuring the roof sides of each of the houses, we collected the data of the roof slope value $(\beta)$ and building orientation value (Or). Table 2 below showed us the measurement result data of the roofs.

Table 2. The roof slope and building orientation value

\begin{tabular}{|c|c|c|c|}
\hline Name & Roof Side & Orientation (Or) & Slope $(\beta)$ \\
\hline \multirow{2}{*}{ House 1 } & $\mathrm{A}$ & $239^{\circ}$ & $23^{\circ}$ \\
\cline { 2 - 4 } & $\mathrm{B}$ & $59^{\circ}$ & $21^{\circ}$ \\
\hline \multirow{2}{*}{ House 2 } & $\mathrm{A}$ & $241^{\circ}$ & $28^{\circ}$ \\
\cline { 2 - 4 } & $\mathrm{B}$ & $61^{\circ}$ & $27^{\circ}$ \\
\hline \multirow{2}{*}{ House 3 } & $\mathrm{A}$ & $336^{\circ}$ & $19^{\circ}$ \\
\cline { 2 - 4 } & $\mathrm{B}$ & $156^{\circ}$ & $20^{\circ}$ \\
\hline \multirow{2}{*}{ House 4 } & $\mathrm{A}$ & $252^{\circ}$ & $24^{\circ}$ \\
\cline { 2 - 4 } & $\mathrm{B}$ & $72^{\circ}$ & $25^{\circ}$ \\
\hline House 5 & $\mathrm{A}$ & $162^{\circ}$ & $7^{\circ}$ \\
\hline
\end{tabular}

To pinpoint the side of the roof, we distinguished the measurement into two sides namely side A and B. We selected the roof sides based on their orientation angles or the direction of the roof surface of each home. The side-A roofs employed an orientation angle $>180$, while the side-B roofs employed an orientation angle of $<180$. Figure 4 showed us the sides of the roofs. 


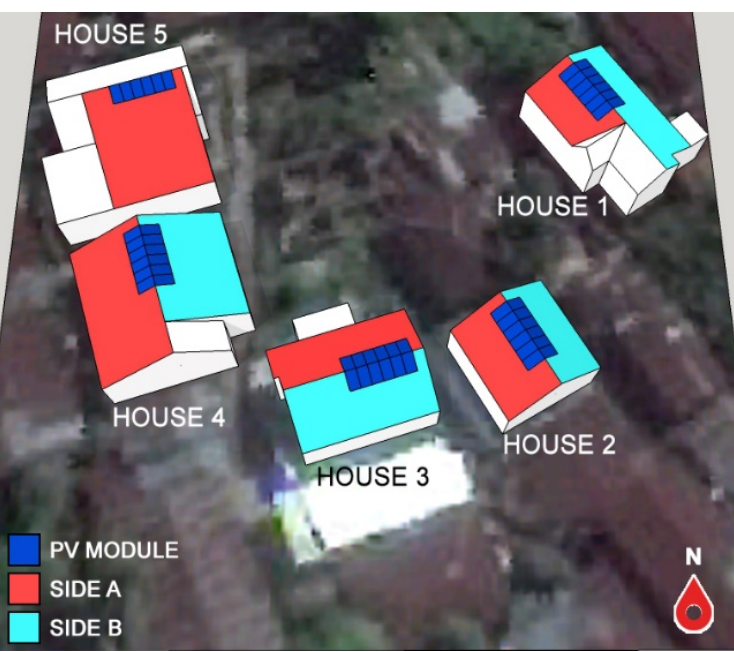

Figure 4. Two Sides of the Rooftop Houses

House 5 only employed one roof side since we could not measure the other roof side due to some obstacles. We obtained the solar irradiation and temperature data by using a software named Meteonorm [22]. The data were recorded for hours, for a one-year period, and there were approximately 8,760 rows of data. Table 3 below showed us 12 rows of solar irradiation and temperature data in Kampung Bukit in 2017 based on certain times and dates of the months.
Table 3. Solar Irradiation per hour

\begin{tabular}{|c|c|c|c|}
\hline Date & Local Time (Lt) & Solar Irradiation (I) & Temperature $\left(\mathrm{T}_{\mathrm{o}}\right)$ \\
\hline 01-Jan & 9 & $355 \mathrm{Wh} / \mathrm{m}^{2}$ & $29.8^{\circ} \mathrm{C}$ \\
\hline 14-Feb & 10 & $925 \mathrm{Wh} / \mathrm{m}^{2}$ & $28.2^{\circ} \mathrm{C}$ \\
\hline 31-Mar & 11 & $907 \mathrm{Wh} / \mathrm{m}^{2}$ & $32.2^{\circ} \mathrm{C}$ \\
\hline 06-Apr & 12 & $1016 \mathrm{Wh} / \mathrm{m}^{2}$ & $33.9^{\circ} \mathrm{C}$ \\
\hline 24-Mei & 13 & $893 \mathrm{Wh} / \mathrm{m}^{2}$ & $33.5^{\circ} \mathrm{C}$ \\
\hline 04-Jun & 14 & $720 \mathrm{Wh} / \mathrm{m}^{2}$ & $31.5^{\circ} \mathrm{C}$ \\
\hline 31-Jul & 15 & $550 \mathrm{Wh} / \mathrm{m}^{2}$ & $33.5^{\circ} \mathrm{C}$ \\
\hline 29-Agu & 16 & $316 \mathrm{Wh} / \mathrm{m}^{2}$ & $33.2^{\circ} \mathrm{C}$ \\
\hline 04-Sep & 17 & $87 \mathrm{Wh} / \mathrm{m}^{2}$ & $32.1^{\circ} \mathrm{C}$ \\
\hline 13-Okt & 6 & $69 \mathrm{Wh} / \mathrm{m}^{2}$ & $25.5^{\circ} \mathrm{C}$ \\
\hline 10-Nov & 7 & $186 \mathrm{Wh} / \mathrm{m}^{2}$ & $25.3^{\circ} \mathrm{C}$ \\
\hline 06-Des & 8 & $442 \mathrm{Wh} / \mathrm{m}^{2}$ & $26.2^{\circ} \mathrm{C}$ \\
\hline
\end{tabular}

\section{Results and Analysis}

Figure 5 showed us the calculation results of each side of the roof containing a comparison chart of irradiation with the PV module output in a 1-month period.

Figure 5 showed us that the highest visible output occurred in May at House 4's side-B roof, while the lowest output took place in December at House 2's side-B roof.

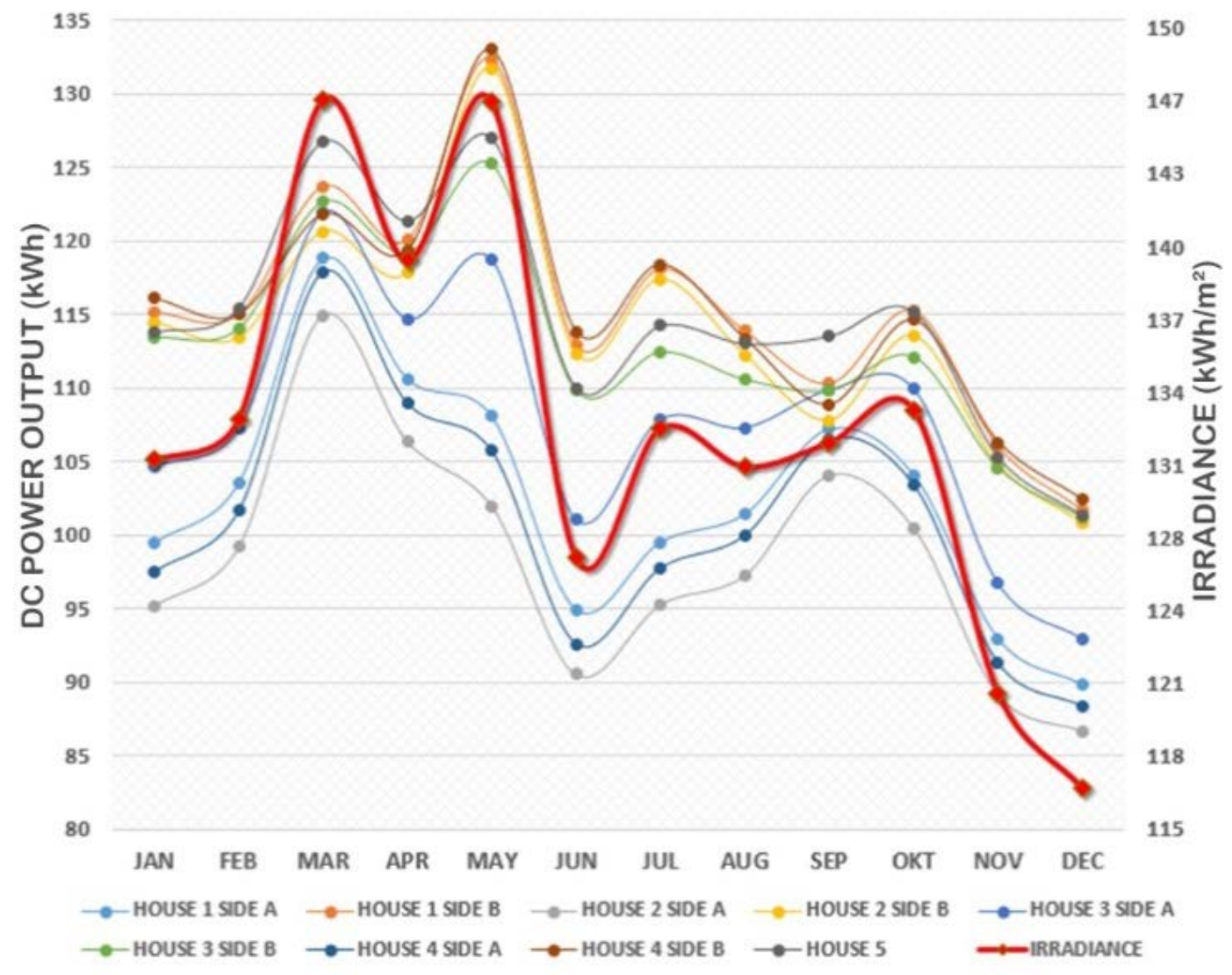

Figure 5. The comparison chart of irradiation with PV module output. 


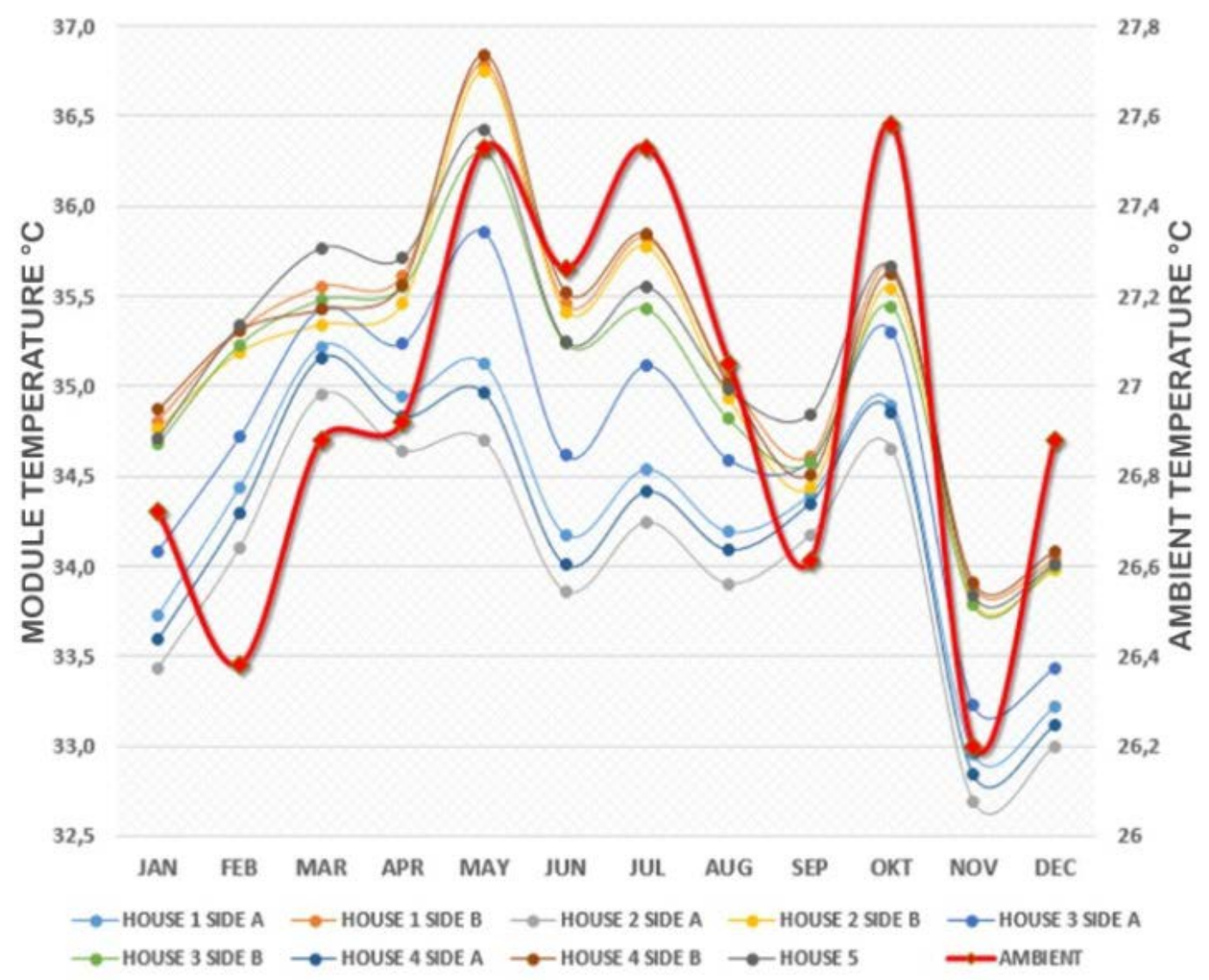

Figure 6. The comparison graph between ambient temperature and PV module temperature

In regard to the calculation, Figure 6 showed us the temperature value of the PV module on each roof side where it contained a comparison graph between the ambient temperature and the PV module temperature in a 1-month period.

Figure 6 showed us that the highest module temperature took place in May at House 4's side-B roof, while the lowest module temperature occurred in November at House 2's side-A roof.

Based on Figures 4 and 5 above, we drew a conclusion that the slope difference highly impacted on the energy output and the PV module temperature due to the receiver angle that was not in line with the direction of sunlight resulting in the lack of direct sunlight beam exposed on the $\mathrm{PV}$ module. As a result, the radiation potential converted to the electrical energy decreased.

We could also observe the calculation result in Table 4. It showed us the data of the operation of the module for one year. The electrical energy output of those five houses showed us that House 4's side-B roof with a 24-degree inclinationand a 72-degree orientation generated the highest power output amounting to $1,265 \mathrm{kWh}$, while House 2's side-A roof with 28-degree inclination and a 239-degree orientation generated the lowest power output amounting to $1,073.9 \mathrm{kWh}$. Therefore, the fluctuation accounted for $17.8 \%$.
Table 4. Electrical Energy Output in One Year

\begin{tabular}{|c|c|c|}
\hline \multicolumn{3}{|c|}{ Electrical Energy Production in One Year (kWh) } \\
\hline & Side A & Side B \\
\hline House 1 & $1,120.2$ & $1,226.9$ \\
\hline House 2 & $1,073.9$ & $1,179.4$ \\
\hline House 3 & $1,250.3$ & $1,238.2$ \\
\hline House 4 & $1,102.5$ & $1,265.0$ \\
\hline House 5 & $1,259.3$ & - \\
\hline
\end{tabular}

To validate the data, we simulated them by using a $\mathrm{PV} * \mathrm{SOL}$ program. The results were then compared to that of the calculation shown in Table 4 . Table 5 showed us the final results.

Table 5. The Simulation Result Comparison Using the One-Year Period Calculation

\begin{tabular}{|c|c|c|c|}
\hline Name & Roof Side & Calculation $(\mathrm{kWh})$ & Simulation $(\mathrm{kWh})$ \\
\hline \multirow{2}{*}{ House 1 } & $\mathrm{A}$ & $1,120.2$ & $1,114.2$ \\
\cline { 2 - 4 } & $\mathrm{B}$ & $1,226.9$ & $1,233.7$ \\
\hline \multirow{2}{*}{ House 2 } & $\mathrm{A}$ & $1,073.9$ & $1,077.4$ \\
\cline { 2 - 4 } & $\mathrm{B}$ & $1,179.4$ & $1,169.8$ \\
\hline \multirow{2}{*}{ House 3 } & $\mathrm{A}$ & $1,250.3$ & $1,215.3$ \\
\cline { 2 - 4 } & $\mathrm{B}$ & $1,238.2$ & $1,194.8$ \\
\hline \multirow{2}{*}{ House 4 } & $\mathrm{A}$ & $1,102.5$ & $1,106.5$ \\
\cline { 2 - 4 } & $\mathrm{B}$ & $1,265.0$ & $1,226.8$ \\
\hline \multirow{2}{*}{ House 5 } & $\mathrm{A}$ & $1,259.3$ & $1,228.3$ \\
\hline
\end{tabular}




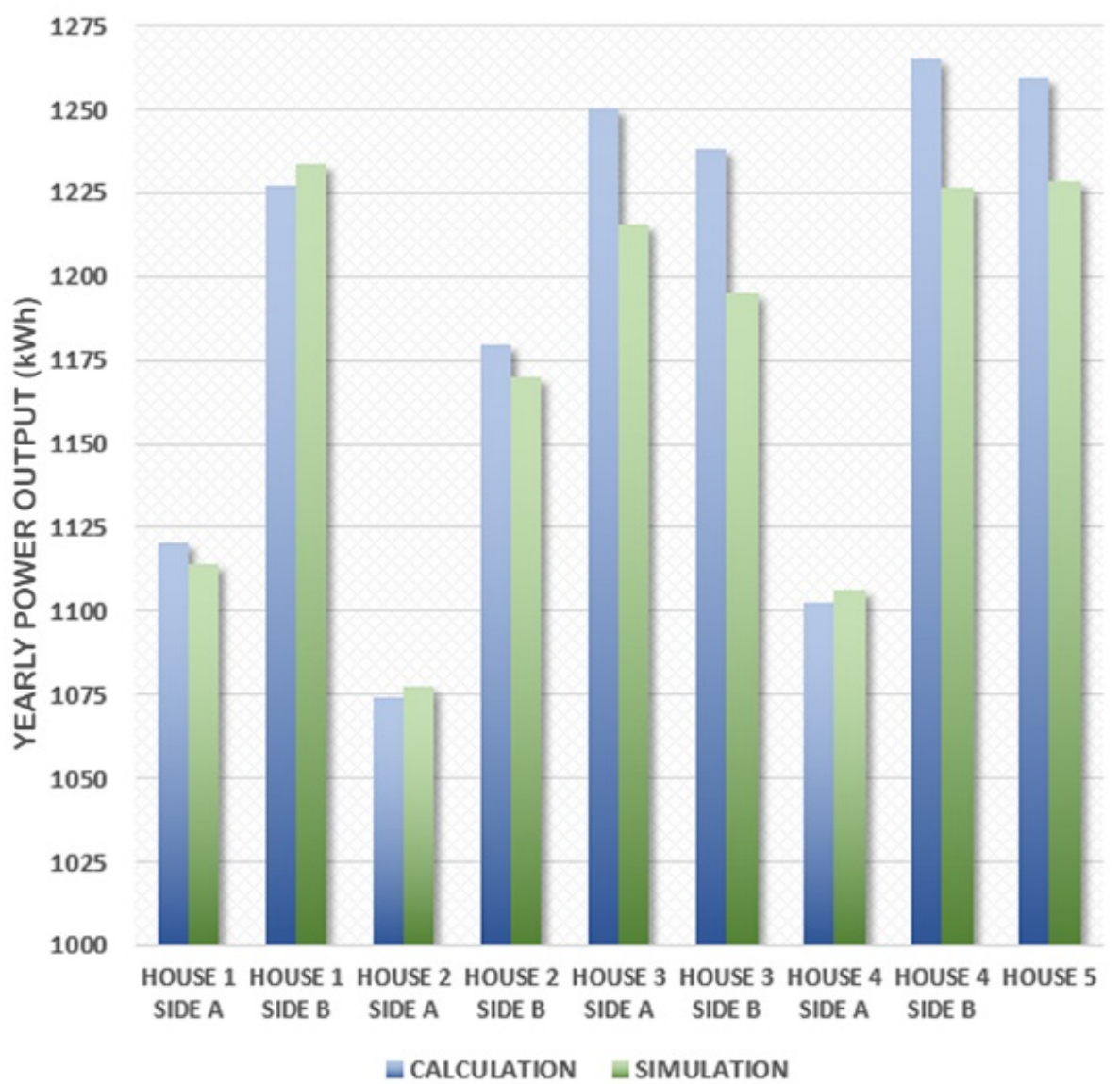

Figure 7. Bar Chart showing the comparison of the outputs between the calculation and simulation results

Figure 7 showed us the comparison data taken from Tabel 5 presented in the forms of a bar chart. The green bars showed us the calculation results, whle the blue bars showed us the simulation results. As having been mentioned above, House 4's side-B roof had the highest output, while House 2's side-A roof had the lowest output.

From the calculation result of the power plant outputs, we found out that House 4's side-B roof with a 24-degree inclination and a 72-degree orientation generated the highest power output amounting to $1,265 \mathrm{kWh} / \mathrm{yr}$, while House 2's side-A roof with 28-degree inclination and a 239-degree orientation generated the lowest power output amounting to $1,073.9 \mathrm{kWh} / \mathrm{yr}$.

When constructing the Solar Home Systems, we observed the importance and significance of the installation, especially when we installed the PV modules integrated to the roofs of each of the houses. Even though we conducted the reserch at the same location, we noticed that diverse roof slopes and orientation significantly impacted on the electrical energy outputs; in fact, it proved to be true by a $17.8-\%$ fluctuation.

When designing the Solar Home Systems, we suggest that we make an in-depth analysis in regard to any of their potential locations where the Solar Home Systems will be installed. We have to make sure that the level of the radiation exposure to the PV module is sufficient enough especially for an installation integrated to the roofs of a house.

We must be confirmed that the specifications of components of the solar power plant that we will use have already met the requirements. When the plant uses atrocious components, the average span of the components' durability will be low. On the other hand, when it uses components above their rating, they will positively impact on the economic value of the Solar Home Systems.

\section{REFERENCES}

[1] H. Goosse, P. Y. Barriat, W. Lefebvre, M. F. Loutre, and V. Zunz, "Energy Balance, Hydrological and Carbon Cycles," in Introduction to Climate Dynamics and Climate Modelling, Cambridge University Press, 2010, pp. 25-57.

[2] I. Sarbu and C. Sebarchievici, Solar Heating and Cooling Systems: Fundamentals, Experiments and Applications. London: Academic Press, 2017.

[3] D. Chwieduk, Solar Energy in Buildings Thermal Balance for Efficient Heating and Cooling, 1st ed. London: Elsevier, 2014. 
[4] S. S. Penner and L. Icerman, Energy, no. v. 2. California: Addison-Wesley Publishing Company, 1984.

[5] M. Woolfson, The Formation of the Solar System Theories Old and New, 2nd ed. London: Imperial College Press, 2014.

[6] S. C. Bhatia, Advanced Renewable Energy Systems. New Delhi: Woodhead Publishing India, 2014.

[7] J. R. Balfour, Introduction to Photovoltaic System Design. Jones \& Bartlett Learning, 2011.

[8] S. Deambi, Photovoltaic System Design: Procedures, Tools and Applications. CRC Press, 2016.

[9] J. A. Duffie and W. A. Beckman, Solar Engineering of Thermal Processes, 4th ed. New Jersey: Jhon Wiley, 2013.

[10] S. C. Capareda, Introduction to Renewable Energy Conversions. CRC Press, 2019.

[11] J. Widén and J. Munkhammar, Solar Radiation Theory. Uppsala: Uppsala University, 2019.

[12] P. I. Cooper, "The Absorption of Radiation in Solar Stills," Sol. Energy, vol. 12, no. 3, pp. 333-346, 1969.

[13] P. Axaopoulos, "Basic principles of solar geometry,” Athens, 2015, pp. 1-21.

[14] P. Axaopoulos, "Solar Radiation on Tilted Surfaces,” Athens, 2015, pp. 1-15.

[15] T. H. Kuehn, J. W. Ramsey, and J. L. Threlkeld, Thermal Environmental Engineering, 3rd ed. New Jersey: Prentice Hall, 1998.

[16] H. Rutkowski, Manual J - Residential Load Calculation: 8th Edition, Full. Arlington: Air Conditioning Contractors of America, 2011.

[17] G. Notton, C. Cristofari, M. Mattei, and P. Poggi, "Modelling of a Double-Glass Photovoltaic Module using Finite Differences,” Appl. Therm. Eng., vol. 25, no. 17-18, pp. 2854-2877, 2005.

[18] F. A. Osman, M. E. Ya’acob, and A. N. Iskandar, "Field measurements of temperature profile for floatovoltaic dryer in the tropics,” in AIP Conference Proceedings, 2017, vol. 1885, no. 1, p. 20015.

[19] D. G. für Sonnenenergie, Planning and Installing Photovoltaic Systems: A Guide for Installers, Architects and Engineers. Earthscan, 2008.

[20] G. Valentin, "Basis of calculation," in Design and Simulation of Photovoltaic Systems Manual, Berlin: Valentin Software, 2015.

[21] A. N. Akpolat, E. Dursun, A. E. Kuzucuoğlu, Y. Yang, F. Blaabjerg, and A. F. Baba, "Performance Analysis of a Grid-Connected Rooftop Solar Photovoltaic System," Electronics, vol. 8, no. 8, p. 905, 2019.

[22] J. Remund, S. Müller, C. Studer, and R. Cattin, Handbook Part I : Software, Global Meteorological Database Version 7, Software and Data for Engineers, Planers and Education, no. March. Bern: Meteotest, 2019. 